\section{Vacant Directorship of Conservation Monitoring Centre}

Although it is not our custom in this Journal to give notice of vacancies in the fields of environment and/or conservation, we are pleased to comply with requests to bring this one to the attention of our world-wide readership as it seems particularly important to these interlocking causes (in effect comprising the core of the environmental movement) that the very best person available be recruited on this occasion.

The vacancy concerns the Directorship of the (world) Conservation Monitoring Centre (CMC) in Cambridge, England, which consists of (1) the Protected Areas Data Unit, (2) the Species Conservation Monitoring Unit, and (3) the Wildlife Trade Monitoring Unit, all located in Cambridge, as well as (4) the Threatened Plants Unit, located at the Royal Botanic Gardens, Kew, near London, UK.

The Director of the CMC reports to the IUCN Directorate-General at Gland, near Geneva, Switzerland. The Director will have full responsibility to plan, organize, and manage, the Centre. Consequently a mature and suitably experienced individual with proven management expertise is sought. No particular scientific discipline is prerequisite, but a doctorate or equivalent indication of experience is desired. Fluency in English is essential, and additional language ability would be useful.

It is likely that the successful candidate will come from a scientific or R\&D background. Salary in the range of £ 10-15,000 per annum, at a negotiable starting-point commensurate with individual qualifications, experience, and requirements. Letters of application, enclosing upto-date curriculum vitae, should be sent as soon as possible to the Director-General, IUCN, Avenue du MontBlanc, 1196 Gland, Switzerland.

\section{Save Trees, Save our Biosphere!}

For the celebration on June 5th of World Environment Day 1982, the Indian Society of Naturalists (INSONA) brought out another issue of stickers entitled 'Save Trees, Save our Biosphere' (Fig. 1).* This was with a view to strengthening support for, and promoting in every possible way, the World Campaign for The Biosphere (Gaekwad \& Oza, 1981; Anon., 1982; Pauling et al., 1982; Polunin, 1982a, 1982b; Worthington, 1982).

The new sticker (in two forms respectively for inner or outer surfaces-for viewing either through glass to which it is affixed or to be stuck on an opaque surface) is designed by INSONA's Fellow, Vinay Trivedi who, for World Environment Day 1981, had designed a 'Save Our Biosphere' sticker depicting the Indian Blackbuck (see

\footnotetext{
* Somewhat similarly this year, UNEP planned a campaign entitled 'For Every Child a Tree', which was furthered in Nairobi in May as we saw by across-street banners, impressive treeplanting ceremonies, and a procession led by a massive brass band.-Ed.
}

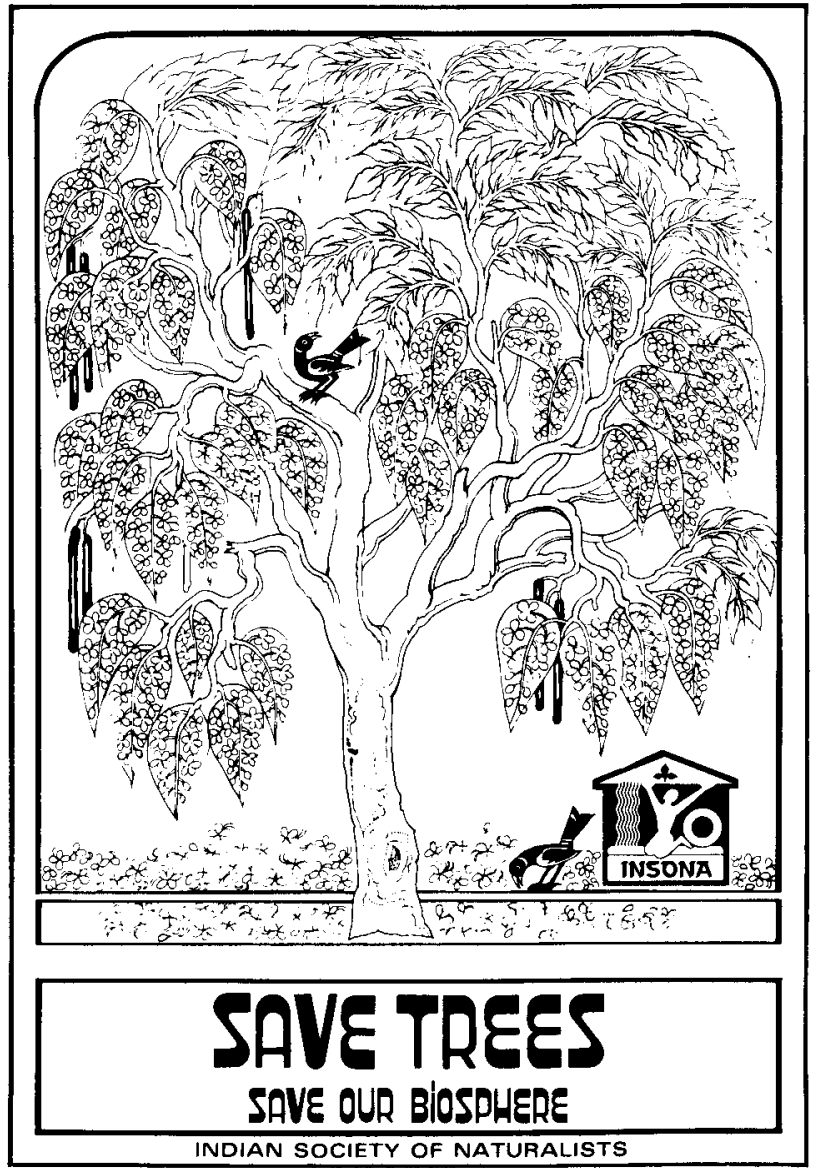

Fig. 1. Uncoloured version of this INSONA sticker which is in 5 colours, $71 / 4 \times 5$ inches $=18.0 \times 12.7 \mathrm{~cm}$, and depicts Cassia fistula.

Gaekwad \& Oza, 1981, and editorial footnote thereto). It is hoped most ardently that these and other, continuing endeavours will go a long way in attracting the attention of the world's population to the fragility of The Biosphere and the paramount requirement of preserving the habitats of the world's most diverse biomes (e.g. Oza, 1981a).

The sticker (Fig. 1), multicoloured, depicts the tropical and warm-temperate genus Cassia (the Indian Laburnums, very showy trees with large ovate leaves and bright-yellow flowers). Cassia fistula (Purging Cassia or Pudding-pipe Tree), distributed also in China and Indomalaysia, and reaching a height of about 18 metres, has been chosen for our 1982 campaign, which is dedicated to tropical forests and their animal denizens, whereas the 1983 campaign will concentrate on conserving plants. The INSONA Symbol, which the sticker carries below on the right, stands for the Society's motto: The Lord in His Grace created this beauteous Universe; the bounden duty to preserve it rests heavily on us.

We have an urgent need to curb the present alarming rate of disappearance of the world's tropical moist forests if we wish to preserve (as of course we do) our most vital species of plants and animals for the allevia- 